\title{
Successful implantation of a Berlin Heart ventricular assist device in ventricular heart failure 23 years after Senning operation
}

\author{
Christoph Schmitz, MD, ${ }^{\mathrm{a}}$ Ralf Sodian, MD, ${ }^{\mathrm{a}}$ Edward Malec, MD, ${ }^{\mathrm{a}}$ Katarzyna Januszewska, MD, ${ }^{\mathrm{a}}$ \\ Ingo Kaczmarek, MD, ${ }^{\mathrm{a}}$ Sieglinde Kofler, MD, ${ }^{\mathrm{a}}$ Christina Bruegger, MD,${ }^{\mathrm{b}}$ Christian Kowalski, MD, \\ Nora Lang, $\mathrm{MD},{ }^{\mathrm{c}}$ and Bruno Reichart, $\mathrm{MD},{ }^{\mathrm{a}}$ Munich, Germany
}

Right (systemic) ventricular (RV) failure in patients with transposition of the great arteries (TGA) after the Senning operation is a well-known late complication. Although double switch operations have been advocated by some groups, ${ }^{1}$ orthotopic heart transplantation (HTx) remains the only definitive option to treat these patients. ${ }^{2}$ However, there is a high mortality rate for patients on transplant waiting lists, and the use of ventricular assist devices (VADs) is often required as a bridge to HTx. ${ }^{3}$

\section{CLINICAL SUMMARY}

We report on a 23-year-old male patient with TGA. At the age of 7 months, the Senning operation was performed. Starting in 2000, RV failure developed. In February 2008, the patient presented at the University of Munich in cardiogenic shock with severe RV dysfunction (ejection fraction $10 \%-$ $15 \%$ ). Because of further deterioration, an intra-aortic balloon pump was implanted and his name was placed on the waiting list. The patient's condition initially stabilized, but 4 weeks later he had a transient ischemic attack, which resolved completely during the next few days. After 7 weeks of intra-aortic balloon pump support, the patient was resuscitated and put on a ventilator because of recurrent ventricular tachycardia and further deterioration. Despite maximal medical support, the patient's condition deteriorated rapidly, and the decision was made to implant a univentricular Berlin Heart EXCOR VAD (Berlin Heart GmbH, Berlin, Germany).

The patient was taken to the operation room. The chest was opened under resuscitation, and normothermic cardiopulmonary bypass was installed via the ascending aorta and superior vena cava, which were cannulated extrapericardially without dissection of the complete cardiac anatomy. After further exposure, the ascending aorta was partially clamped and a MEDOS arterial cannula (12 mm) (Medos Medizintechnik AG,

\footnotetext{
From the Departments of Cardiac Surgery, ${ }^{\mathrm{a}}$ Anesthesiology, ${ }^{\mathrm{b}}$ and Pediatric Cardiology, ${ }^{\mathrm{c}}$ University of Munich, Munich, Germany.

Disclosures: None.

Received for publication May 21, 2008; accepted for publication Sept 17, 2008; available ahead of print April 3, 2009.

Address for reprints: Christoph Schmitz, MD, Department of Cardiac Surgery, University of Munich, Marchioninistr. 15, 81377 Munich, Germany (E-mail: Christoph. Schmitz@med.uni-muenchen.de).

J Thorac Cardiovasc Surg 2010;139:e30-1

$0022-5223 / \$ 36.00$

Copyright (c) 2010 by The American Association for Thoracic Surgery doi:10.1016/j.jtcvs.2008.09.044
}

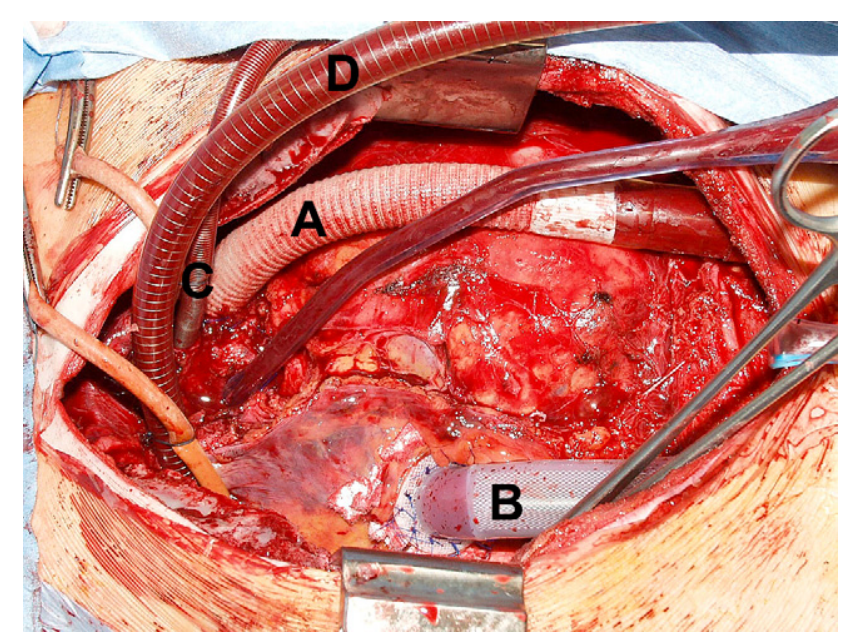

FIGURE 1. Intraoperative view of the connection sites of a univentricular Berlin Heart EXCOR (Berlin Heart GmbH; Berlin, Germany) assist device in a patient after the Senning operation. A, Berlin Heart outflow cannula. B, Berlin Heart inflow cannula. C, Cardiopulmonary bypass arterial cannula. $\mathrm{D}$, Cardiopulmonary bypass venous cannula.

Stolberg, Germany) was sewn end to side to the ascending aorta. A Berlin Heart inflow cannula (12 mm) (Berlin Heart $\mathrm{GmbH}$, Berlin, Germany) was connected to the free wall of the physiologic left atrium (anatomic right atrium) via an extrapericardial access (Figure 1). The Berlin Heart VAD $(80 \mathrm{~mL})$ (Berlin Heart $\mathrm{GmbH})$ was started, and the patient was gradually weaned from cardiopulmonary bypass. The chest was closed, and the patient was transferred to the intensive care unit under hemodynamically stable conditions.

The patient was neurologically intact postoperatively. He was weaned from the ventilator on the fourth postoperative day and transferred to the normal ward on the fourteenth postoperative day. Currently the patient is mobilized and awaiting HTx.

\section{DISCUSSION}

The atrial switch operation has been almost completely abandoned in the treatment of TGA because of the probability of development of RV failure after 10 to 20 years. However, there are a certain number of adult patients who were treated with different types of atrial switch operations before the introduction of the arterial switch operation beginning in the 1980s. 
There are several options to address RV failure in patients after atrial switch operations. Some groups advocate the conversion from the atrial to an arterial switch operation, ${ }^{1}$ and others support orthotopic HTx. ${ }^{2}$

Although we are generally in favor of HTx, we also face the general problem of a lack of donors for patients awaiting HTx. ${ }^{4}$ A bridge to transplantation with different VADs has been one answer for patients whose condition deteriorates while on the waiting list, but using VADs in patients with "abnormal" anatomy presents a surgical challenge, especially after the Senning operation.

As patients with TGA rarely show left ventricular (LV) dysfunction, the use of a univentricular VAD should be adequate for most, if not all, patients. To the best of our knowledge, there is no single report in the literature describing biventricular mechanical circulatory support in patients with ventricular failure after atrial switch operation. Installing an RV assist device is easy, because the enlarged and thickened left atrium is an optimal structure for the inflow conduit. The right ventricle may be another option for the LV assist device inflow conduit, but it requires dissection and exposure of the right ventricle and ventricular fibrillation, or even cardioplegic cardiac arrest as described by George and colleagues. ${ }^{5}$ However, if biventricular support should be required, installing an LV assist device might be done by cannulating the superior vena cava as the right atrium, which is "in the middle" of the heart and completely hidden by the left atrium. Another option might be the apex of the LV. Sewing a graft to the pulmonary artery may be more difficult than normal, because the main pulmonary artery in patients with TGA is often located behind the ascending aorta.

\section{CONCLUSIONS}

Despite these difficulties, implantable VADs in failing ventricles have the potential to allow hemodynamic, metabolic, and pulmonary recovery. The implantation of VADs in children and young adults with congenital heart disease requires modifications of the perioperative management and standard surgical techniques as described.

\section{References}

1. Mee RB. Severe right ventricular failure after Mustard or Senning operation. Twostage repair: pulmonary artery banding and switch. $J$ Thorac Cardiovasc Surg. 1986;92:385-90.

2. Kirjavainen M, Happonen JM, Louhimo I. Late results of Senning operation. J Thorac Cardiovasc Surg. 1999;117:488-95.

3. Schmauss D, Schmitz C, Malec E, et al. Right-sided heart reperfusion in pediatric patients with left ventricular assist device. J Thorac Cardiovasc Surg. 2008;135: 953.

4. Komoda T, Hetzer R, Lehmkuhl HB. Destiny of candidates for heart transplantation in the Eurotransplant heart allocation system. Eur J Cardiothorac Surg. 2008;34:301-6 [Epub 2008 Apr 14].

5. George RS, Birks EJ, Radley-Smith RC, Khaghani A, Yacoub M. Bridge to transplantation with a left ventricular assist device for systemic ventricular failure after Mustard procedure. Ann Thorac Surg. 2007;83:306-8.

\section{Ventricular septal defect repair in an infant with severe pulmonary hypertension and preoperatively diagnosed left ventricular noncompaction}

Yuki Sasaki, MD, ${ }^{\text {a }}$ Tsukasa Ozawa, $\mathrm{MD}, \mathrm{PhD},{ }^{\mathrm{a}}$ Hiroyuki Matsuura, $\mathrm{MD}, \mathrm{PhD},{ }^{\mathrm{b}}$ Tsutomu Saji, MD, PhD,

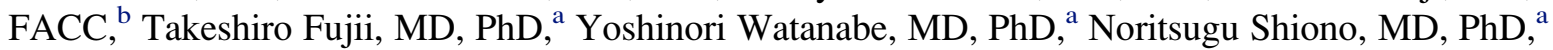
Yoshinori Takanashi, MD, PhD, ${ }^{\mathrm{c}}$ and Nobuya Koyama, $\mathrm{MD}, \mathrm{PhD},{ }^{\mathrm{a}}$ Tokyo and Sizuoka, Japan

\footnotetext{
From the Department of Cardiovascular Surgery ${ }^{\mathrm{a}}$ and First Department of Pediatrics, ${ }^{\mathrm{b}}$ Toho University Omori Medical Center, Tokyo, Japan; and Atami Hospital, International University of Health and Welfare, ${ }^{\mathrm{c}}$ Sizuoka, Japan.

Disclosures: None.

Received for publication May 22, 2008; accepted for publication Sept 19, 2008; available ahead of print March 27, 2009.

Address for reprints: Tsukasa Ozawa, MD, PhD, Department of Cardiovascular Surgery, Toho University Omori Medical Center, Omori-nishi 6-11-1, Ota-ku, Tokyo, Japan, 143-8541 (E-mail: cbc02537@nifty.com).

J Thorac Cardiovasc Surg 2010;139:e31-3

$0022-5223 / \$ 36.00$

Copyright (c) 2010 by The American Association for Thoracic Surgery

doi:10.1016/j.jtcvs.2008.09.039
}

Intracardiac repair for congenital heart disease complicated by left ventricular noncompaction (LVNC) has been rarely described. This is the first report of ventricular septal defect (VSD) repair in an infant with severe pulmonary hypertension $(\mathrm{PH})$ and preoperatively diagnosed LVNC.

\section{CLINICAL SUMMARY}

A 2-month-old infant with a VSD was referred to the Toho University Omori Medical Center Department of 